Bull. Mater. Sci., Vol. 15, No. 1, February 1992, pp. 55-65. (C) Printed in India.

\title{
Materials and methods of construction to resist the effects of cyclones
}

\author{
J SHANMUGASUNDARAM, S ARUNACHALAM and \\ M ARUMUGAM \\ Structural Engineering Research Centre, Madras 600113, India
}

\begin{abstract}
Failures of thousands of dwellings and that of a large number of engineered and non-engineered buildings and other industrial structures, caused by cyclones every year are of serious concern to professional engineers, scientists and researchers. The quality of common building materials used in the coastal regions of India such as stone and brick masonry, timber, steel and reinforced cement concerte, tiles, $\mathrm{AC}$ and other roofing sheets and also the effective methods of construction adopted, significantly affect the strength of structures in resisting severe cyclones. This paper discusses the common deficiencies on the properties of the materials used for walls and roofing of housing and other industrial structures, in resisting cyclonic wind forces and the ineffective construction practices leading to poor strength of overall structure. The paper also suggests some of the simple techniques to improve the cyclonic resistance of the structures.
\end{abstract}

Keywords. Cyclone; structures; building materials; construction; failures; mitigation.

\section{Introduction}

Tropical cyclones belong to the family of atmospheric disturbances, where wind rotates around an area of low pressure and are formed in the ocean regions between 5 and 30 degree latitudes on either side of the Equator (Venkateswarlu et al 1985). A tropical cyclone is a large rotating storm with a giant vortex of 150 to $1000 \mathrm{~km}$ across and 12 to $15 \mathrm{~km}$ high. When the wind speed of the atmospheric disturbance exceeds $17 \mathrm{~m} / \mathrm{s}$, it is termed as tropical cyclone, but the cyclone is known to cause structural damage when the sustained wind speed exceeds $33 \mathrm{~m} / \mathrm{s}$. In India, cyclones occur during April and May and also from October to December. Coastal areas of India, especially the east coast, are severely affected due to cyclones every year and experience heavy losses to both life and property. Housing sector is normally the worst affected during cyclones in terms of damage to structures and losses to human life.

During earlier periods, in the management of cyclone disasters, much of the attention was mainly focussed on rescue, relief and rehabilitation measures. However, there is now an increased awareness on mitigation of human misery and loss of property, besides post-disaster relief works. The quality of common building materials used in the coastal regions of India such as, stone and brick masonry, timber, steel, reinforced cement concrete, tiles, asbestos, corrugated roofing sheets such as asbestos corrugated sheets, thin galvanized iron sheets and others and also the different methods of construction adopted, significantly affect the strength of structures in resisting severe cyclones. Planning in advance on the choice of suitable construction materials and methods of construction in cyclone-prone regions will reduce the damage to dwellings and other structures. This needs understanding of the characteristics of high wind, wind effects on structures, and of different types of materials, and construction methods currently in vogue in cyclone-prone regions. Based on the post-disaster damage surveys on buildings and structures, conducted by SERC, Madras and by other 
organizations in various parts of the world, the performance of different types of materials and methods of construction during the cyclones has been found similar, which indicates that there is a need to focus significant attention on the types of materials used and methods of construction adopted. This paper discusses the types of materials used for walls and roofing of houses, and other industrial structures in resisting cyclonic wind forces and methods of construction that could afford reasonable protection against high winds. This paper also suggests some of the simple techniques to improve the structural resistance to cyclones.

\section{Types of materials}

The roofing materials used commonly in the coastal regions of India are (a) Thatch, (b) clay tiles (Mangalore and country tiles), (c) asbestos cement or metal sheets and (d) reinforced cement concrete.

\subsection{Failures of roofing materials}

2.1a Thatch: Roof thatching is widely used in India to cover majority of rural houses, and temporary and simple structures in urban areas (Annamalai and Shanmugasundaram 1989). They are readily available, low in cost, easily laid and do not require special tools or skills. The expected life of thatching is about three years.

Generally thatched roofs will be blown away during the cyclone. This is due to their low dead weight, poor strength of material and inadequate fixing of the cladding materials to rafters. The fixing requirements should be based on the magnitude of uplift forces which are likely to be experienced by the roof cladding. It was reported that all the thatched huts were totally destroyed in the affected areas of Andhra Pradesh during the 1977 cyclone (Madhava Rao et al 1979, 1982).

Though thatch cannot be considered as a durable material, its use by the economically weaker sections of the society will continue because of its simple, quick and reasonably low-cost construction.

2.1b Clay tiles: Failure of roof cladding due to uplift is one of the common failures observed during cyclones. It should be mentioned here that the value of weight density of the roof cladding material plays a significant role in resisting the uplift forces. Table 1 gives the values of self-weight per unit area of AC sheets, GI sheets, clay tiles and reinforced concrete, which are normally used for roofing, from which the relative merits of these materials can be inferred.

Table 1. Self-weight of different roofing materials.

\begin{tabular}{ll}
\hline Roof cladding material & Self weight $\left(\mathrm{kg} / \mathrm{m}^{2}\right)$ \\
\hline AC sheets & 18.5 \\
GI sheets (16 gauge) & $10 \cdot 0$ \\
Tiles (i) Mangalore type & 54.0 \\
$\quad$ (ii) Country type & 65.0 \\
RCC & 250.0 (for $10 \mathrm{~cm}$ thick) \\
\hline
\end{tabular}




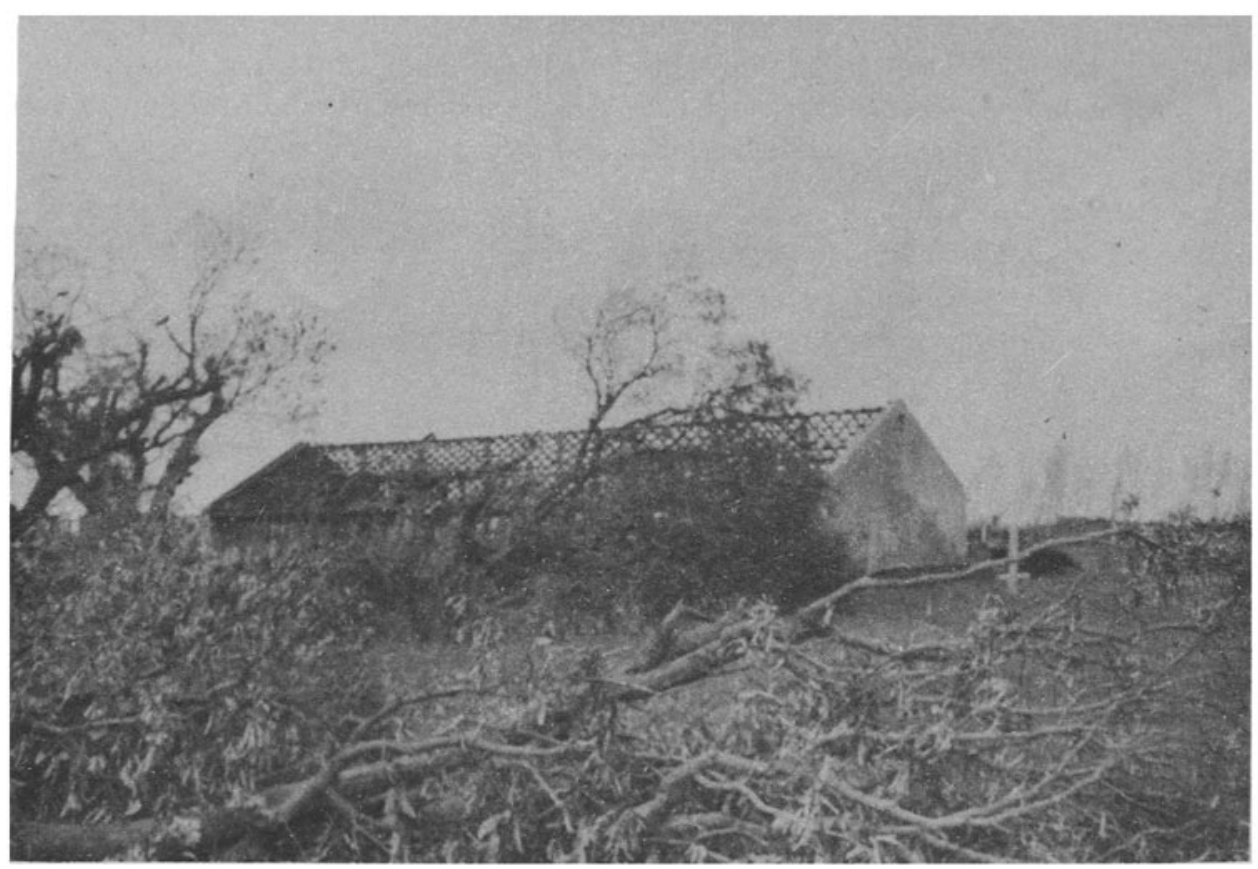

Figure 1. Complete failure of a tiled roof of a shed.

Clay tiles are mostly used in huts, sheds and small school buildings. In cyclone-prone regions country tiles or half-tiles made with local clays, are considered better than Mangalore tiles due to their higher dead weight (multi-layer).

As discussed earlier, because of their low dead weight, the damage to tiled roof cladding is heavy during cyclone. Figure 1 shows complete failure of a tiled roof of a shed during the 1989 cyclone at Kavali in Andhra Pradesh. In some cases, the mortar beddings at suitable spacings are used along hips and ridges to tie down the roof against uplifting forces.

2.1c AC or GI sheets: Asbestos cement sheets as roof covering are very popular in industrial gabled structures, and also in houses with sloping roofs in urban areas. The cost of AC sheet roofing along with supporting framework is about $15 \%$ lower than Mangalore tile roofing (Venkateswarlu and Muralidharan 1978). Galvanized iron or metal sheets used for roofing in urban areas are not popular because they are expensive and are not durable in corrosive coastal environment.

Failure of roofing with $\mathrm{AC}$ sheets is very common during cyclone. It was observed during the post-disaster survey on damage suffered by buildings and structures, due to the 1989 cyclone at Kavali, Andhra Pradesh, that almost all buildings with pitched roofs covered with $\mathrm{AC}$ sheets sustained heavy damage due to blowing off of the cladding. In many of the low-rise industrial structures, the AC claddings were tied to the rafters/purlins by means of ' $\mathrm{J}$ ' bolts (instead of ' $\mathrm{U}$ ' bolts). The cyclonic wind forces, however, fluctuate in nature and hence these $J$ bolts were forced to flatten out, weakening the strength of connection between the cladding and the purlins/rafters. 
Further, in some cases they were tied with simple nailing without proper washers etc. even near the eaves which are more vulnerable locations of cladding damage.

The following are some of the common deficiencies in the $\mathrm{AC}$ sheet roofing system observed during inspection of cyclone affected areas.

(i) Insufficient hook bolts were used and usually only one in the corners of each sheet.

(ii) Most hook bolts were fixed through the overlap or the first corrugation rather than through the second.

(iii) No extra fixings were used in regions subjected to high suction forces.

(iv) Unsupported AC sheet overhangs were in excess of $450 \mathrm{~mm}$.

(v) Often multi-corrugation side laps were left as such, rather than removing excess sheet width.

2.1d Reinforced concrete: Reinforced concrete is predominantly used for flooring/ roofing in urban areas. Because of its high dead weight $\left(2500 \mathrm{~kg} / \mathrm{m}^{3}\right)$ in comparison to other roofing materials cited above, it can offer adequate resistance to uplift forces. It is also preferred due to its low maintenance cost and higher service life, although its initial cost is relatively high.

Failures suffered by RC roofs in single and double storeyed residential and office buildings due to cyclones were found to be limited in number. However, care should be exercised to provide proper cover for the reinforcement to avoid corrosion, particularly, for structures constructed along the coastal regions.

\subsection{Failures of walling materials}

The common types of construction adopted for walls in houses, buildings and other structures include mud walls, masonry walls with bricks or stones, walls with unreinforced hollow concrete blocks, precast RC panels, RC columns with infilled brick work etc.

Mud walls are mostly used for rural houses and small sheds with thatched roofs and owing to their poor material strength, they are severely battered by cyclonic wind forces which are accompanied by torrential rains.

Brick masonry walls are widely used in many of the residential buildings. Where stones are locally available, stone masonry is also adopted for construction of walls. In many of the low-rise industrial buildings, brick masonry walls with intermediate plasters are extensively used. Such types of construction are also used in the case of free standing compound walls of many of the school, office, and industrial buildings.

Failure of a large number of brick masonry walls has been observed during many of the cyclones. High intensity wind causes masonry walls to collapse due to their inadequate lateral resistance. The collapse of the brick wall of an industrial structure due to the 1989 cyclone is shown in figure 2 .

The quality of bricks, workmanship, spacing of pilasters, size of the panels and the presence of bond beams or other lateral supports influence the lateral resistance of the wall structure.

Collapse of masonry walls in many of the industrial structures has led to progressive collapse of the roof system, when adequate connections between the wall and the roof system are not provided.

Generally, walls constructed with RC columns with infilled brickwork, performed better during cyclones. 


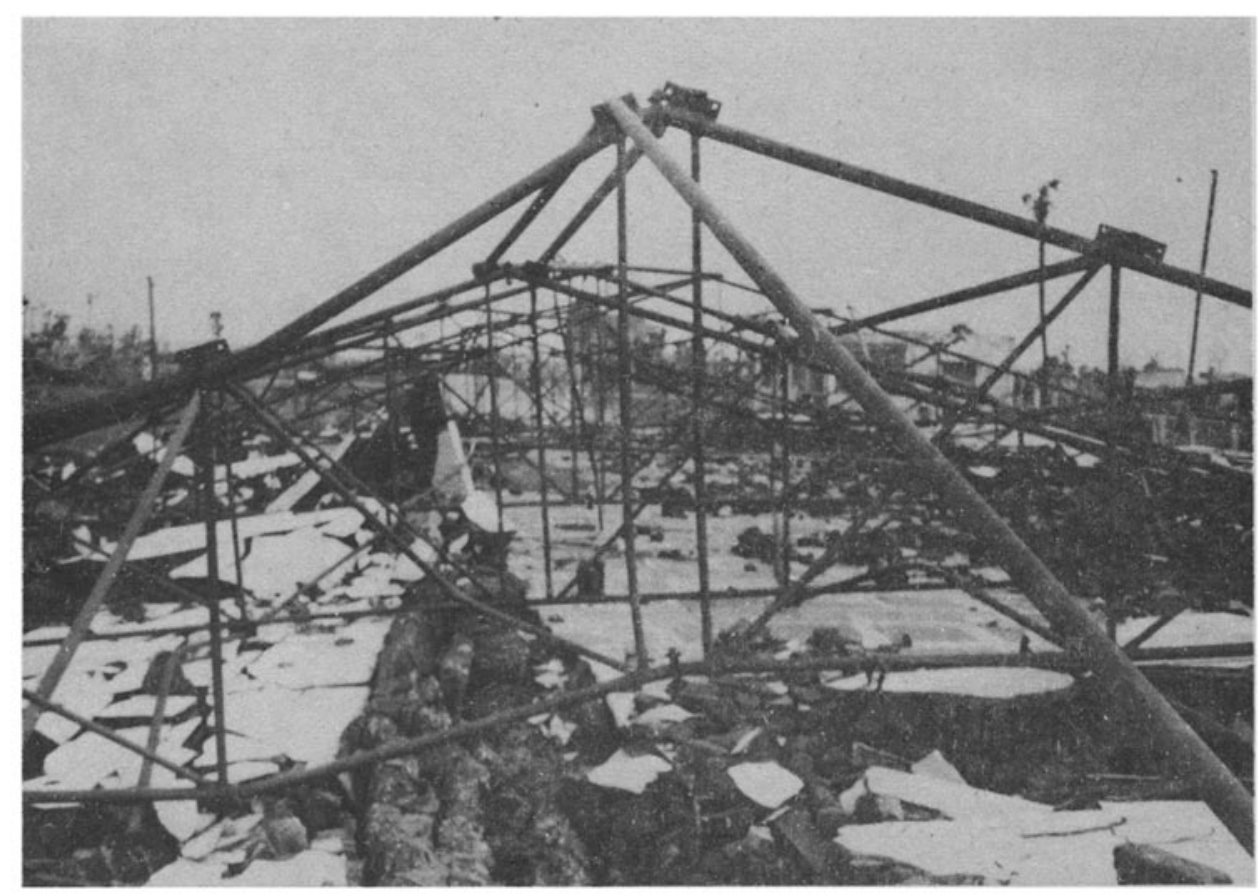

Figure 2. Collapse of brick wall of an industrial structure.

\section{Improvements in materials and methods of construction to better withstand cyclones}

Houses with thatched roofs and mud walls extensively being constructed in coastal regions basically have inadequate resistance to high cyclonic wind forces and collapse of such houses is expected during cyclones. It is, hence, suggested that their use can be made to a limited extent. The blowing off of the thatched roofs can be prevented by tying the roof with rope, wires or metal straps and by anchoring it to the ground.

The durability of the mud walls can be improved by waterproof treatment of the exterior and interior surfaces. Use of non-erodable mud, based on bitumen cutback, is suggested for mud houses (Mathur 1984).

Some of the factors which contribute significantly towards the performance of pitched roof buildings during cyclones include proper selection of roof pitch, type of roof framing (gable or hip type), type of bolts for connecting the fasteners ( $J$ type or $\mathrm{U}$ type) and the number and spacing of these bolts in each cladding sheet.

It is reported, based on wind tunnel investigations, that when the pitch of the roof ranges between 30 and 40 degrees, the wind force on the roof cladding is minimum. This is indicated in figure 3 , wherein it is seen that for various aspect ratios, the value of suction pressure coefficient, $C_{p}$, for the above range of the pitch angle is found to be minimum.

Pitched roof buildings with both hip and gable types are normally constructed in the coastal regions for residential and other low-rise industrial structures. However, it has been observed in many post-disaster cyclone damage surveys in India (Venkateswarlu and Muralidharan 1978; Shanmugasundaram et al 1990a,b), that hipped roofs survived better than gabled roofs. Such an observation was also reported 

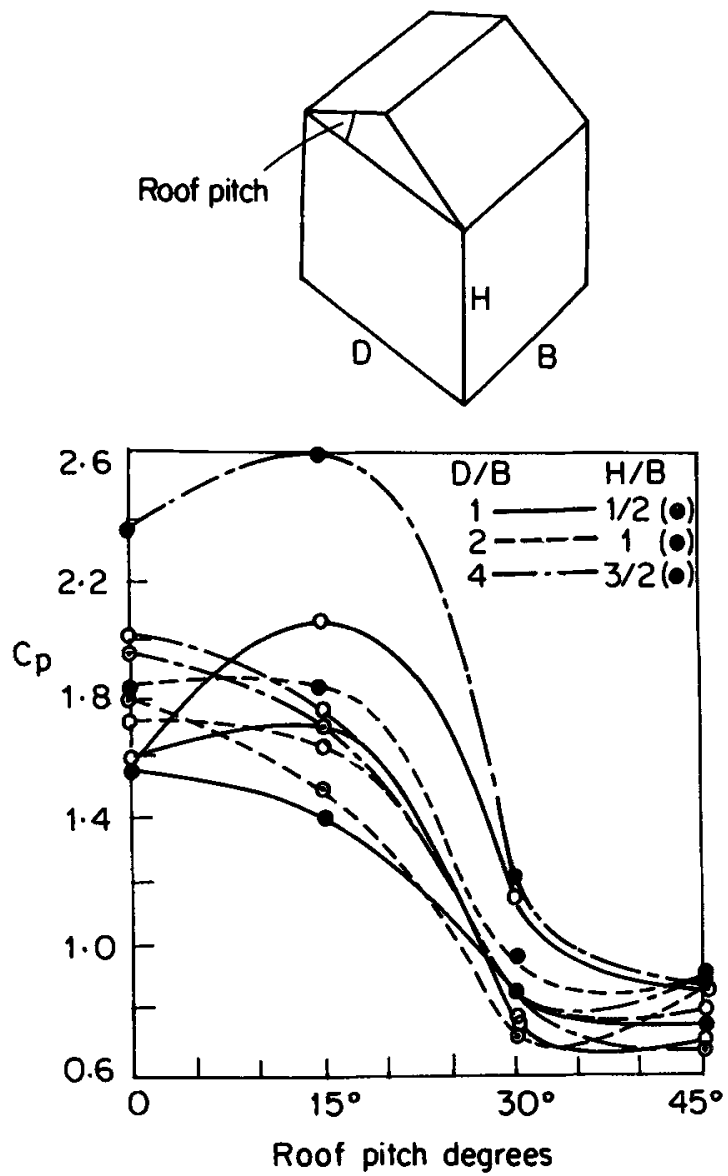

Figure 3. Average maximum suction of roofs of different pitches.

by Zornig and Sherwood (1969), during the hurricane Camille in 1969 and by Wittenoom (1975) in Australia and by Sparks et al (1985) during hurricane Elena in the United States. Wind tunnel experiments on the performance of structures with hipped and gabled roofs, subjected to wind action also show evidence to the above fact that hipped roofs can resist the wind forces better compared to gabled roofs (Meecham et al 1989). Based on wind tunnel investigation on building models with the above types of roof, simulating open terrain conditions, the peak negative pressure coefficients were determined for various azimuth angles and they are presented in figure 4. From the above experiment the following conclusions were reported.

(i) Hipped roofs have several advantages over similarly constructed gabled roofs.

(ii) The distributed mean pressure on the first full span truss of the gabled roof can be roughly twice the value on the similar truss of a hipped roof. This implies that damage by failure of end gabled roof trusses may occur at wind speeds of the order of $70 \%$ of the wind speed causing failure of the first full span truss of a hipped roof. (iii) The local negative peak pressures on the gabled roof can be roughly $50 \%$ higher than those on the hipped roof.

(iv) Hipped roofs possess greater in-plane diaphragm strength (i.e. folded plate action). 

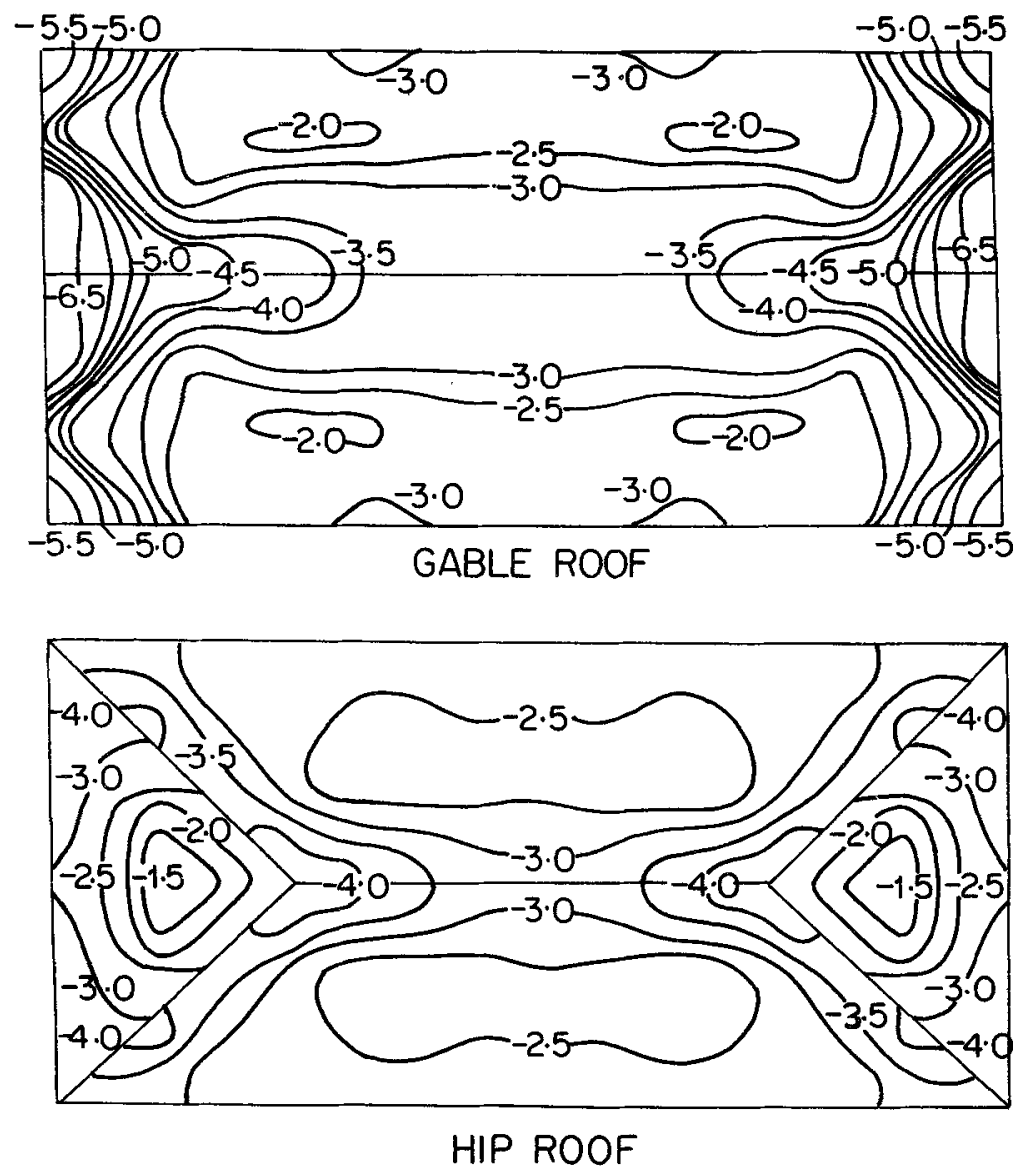

Figure 4. Worst peak negative pressure coefficients - all azimuths - open country exposure.

Anchorage, bracing and continuity are the prime factors influencing the structural integrity. These conditions respectively imply that (Shanmugasundaram et al 1989; Ministry of Local Government, Sri Lanka 1980):

(i) every part of a structure should be firmly tied or anchored back to a secure point which can safely resist all the forces acting on it,

(ii) roof and walls must be properly braced to prevent tilting, sliding and rotation,

(iii) every part of the structure must be properly connected to each other member along the "strength chain" from cladding to foundations.

For example, proper connections between various structural elements of the roofing system are essential in minimizing failure of roofing due to cyclones. As stated earlier, conventionally used $\mathrm{J}$ bolts for connecting the cladding sheets to rafters/purlins are found to be ineffective in resisting uplift cyclonic wind forces. By providing $U$ boits in place of $\mathrm{J}$ bolts at closer intervals, the flattening of $\mathrm{J}$ bolts and its consequent weakening of the connections can be prevented. Galvanized $U$ hook bolts, of $6 \mathrm{~mm}$ diameter with suitable nuts, diamond-shaped curved metal washers, and bituminous or rubber underwashers are recommended as shown in figure 5, for fixing the $\mathrm{AC}$ 


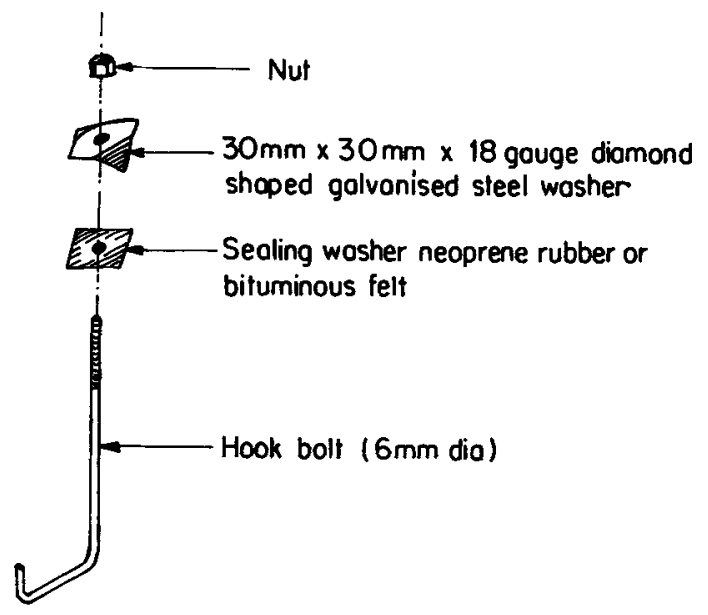

Figure 5. Hook bolt and washer assembly.

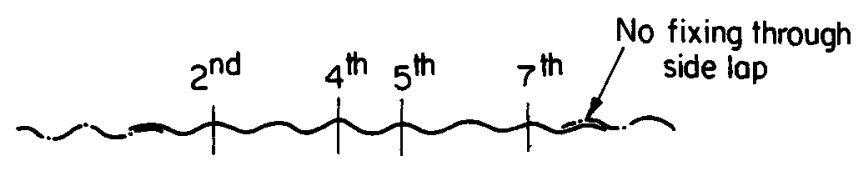

Four fixing per sheet
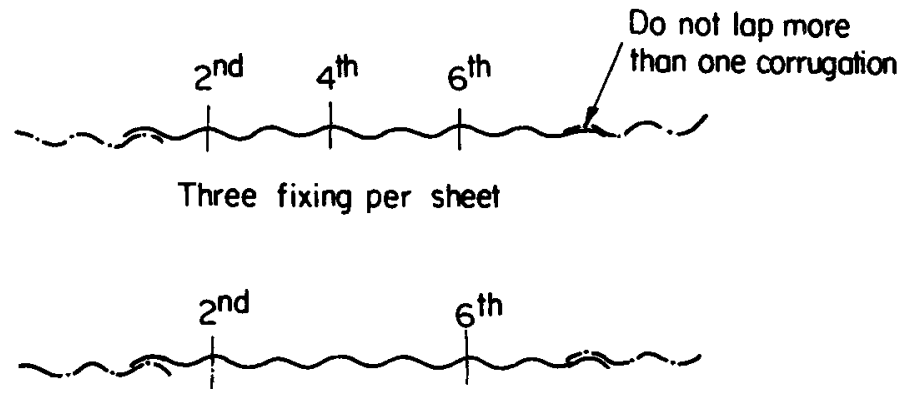

Two fixing per sheet

Figure 6. Hook bolt location and side lap.

cladding sheets. The number and spacings of the hook bolts shall be symmetrical and shall be as shown in figure 6.

In the case of roof with tile cladding, by providing concrete restraining strips over the tiles, the dead load of the cladding unit can be increased, which is beneficial in resisting the uplift forces. The spacing of these strips shall be $1.5 \mathrm{~m}$ which can be reduced to $1.2 \mathrm{~m}$ near gable ends. Further, these strips can be tied to the main rafters by tying down the reinforcing bar provided in the concrete strip, using $30 \times 24 \mathrm{~mm}$ gauge GI straps and $50 \times 12 \mathrm{~mm}$ gauge nails, as shown in figure 7 .

In the case of masonry walls, in the majority of house constructions in India, a continuous band of reinforced concrete beam is provided at plinth level to take care of differential settlement. When the soil conditions are poor, a bond beam is also provided at lintel level. Floor and roof slabs of reinforced concrete provide adequate 


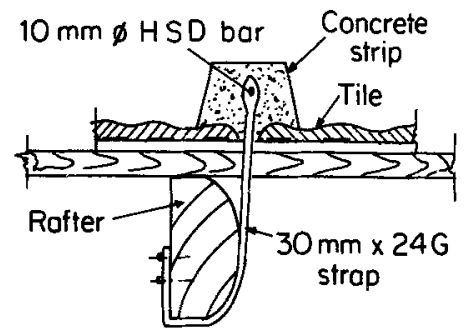

(a)

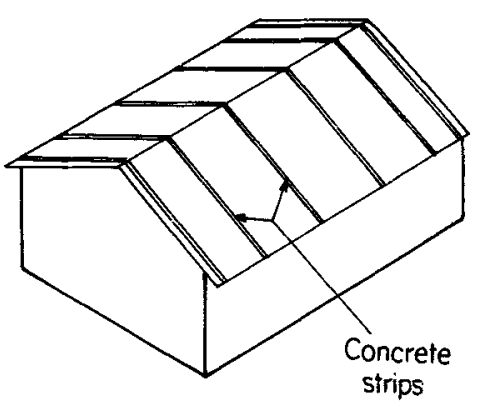

(b)

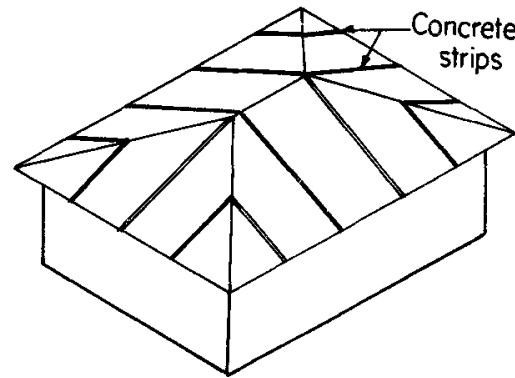

(c)

Figure 7. Holding down Calicut tiles using concrete strips. (a) connection of concrete strip to rafter, (b) two-way sloped roof and (c) four-way sloped roof.

restraint to the masonry walls at top. Reinforced bond beams are to be provided in shed-type structures at the top to increase their lateral resistance against wind forces. Also, provision of anchorage, in the form of tie-down bolts, between foundation and bond beam is essential for further improving the resistance against cyclonic forces as shown in figure 8.

Failure of a large number of gable walls or side walls in low-rise industrial buildings was observed during cyclones, and it was mainly due to inadequate lateral resistance of the wall to resist high wind forces. By reducing the spacing of pilasters, and by providing continuous $\mathrm{RC}$ bond beam at the top, the lateral resistance of the wall can be improved. Provision of RC columns to support the roof trusses (instead of brick pilasters) with infilled brickwork will increase the lateral resistance of the wall. This also helps in restricting the extent of damage to the panels only, in the event of a failure due to cyclone, thereby preventing the progressive collapse of the roof truss system.

The integrity of the structure in resisting the cyclonic forces can also be improved by providing suitable roof bracing between the trusses. 


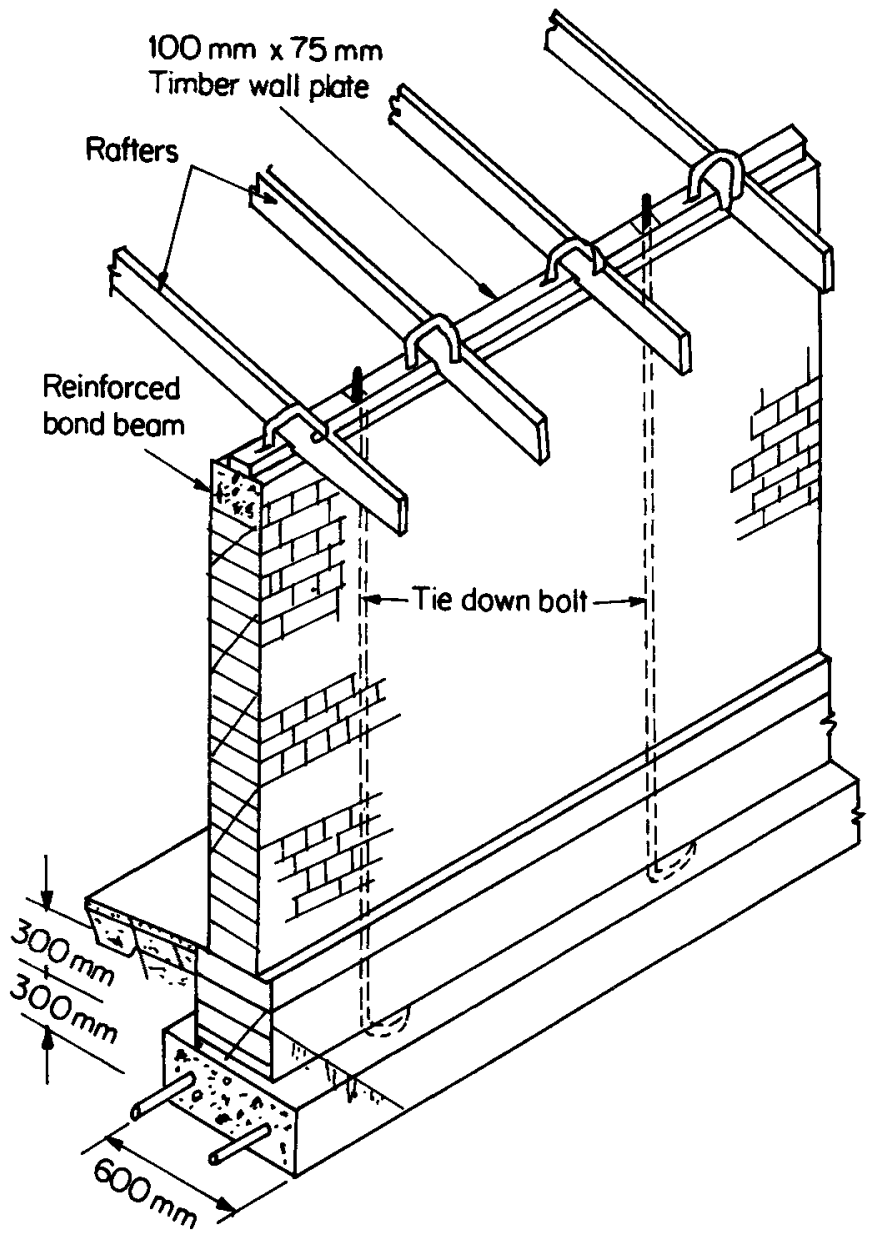

Figure 8. Fixing of walls to the foundation using tie-down bolts.

The resistance of free-standing compound walls to lateral high wind forces can be improved by either staggering the walls and/or by reducing the spacing of the brick pilasters or RC pillars or by tying down the wall to the foundation using tie-down bolts at suitable intervals.

\section{Conclusions}

Tropical cyclones frequently occur along the coastal regions of India and they cause colossal loss of life and property every year. This paper presents, in brief, the damage suffered by various types of buildings and structures during cyclones. The performance of different construction materials commonly used for walls and roofs, in the coastal regions, has been briefly reviewed, and some of the deficiencies observed in the current practice, which aggravate failure chances of the structure, have been discussed. Simple techniques of construction, to improve the resistance of structures in better withstanding the cyclonic forces have also been suggested. 


\section{Acknowledgements}

The authors are grateful to Dr T V S R Appa Rao for suggestions during the preparation of this paper. The assistance rendered by other staff of SERC, Madras is gratefully acknowledged.

\section{References}

Annamalai G and Shanmugasundaram J 1989 Research Report, SERC, Madras

Madhava Rao A G, Annamalai G, Ramachandra Murthy D S, Djugash A C R and Jayaraman R 1979 \& 1982 Design for low cost houses-A compendium (New Delhi: CECON/SERC) vols 1, 2

Mathur G C 1984 Proc. Int. Conf. on natural hazard mitigation, Research and Practice, Small Buildings and Community Development, CIB/W-73, New Delhi

Meecham D, Surry D and Davenport A G 1989 Proc. Int. Conf. on Recent Advances in Wind Engineering, (ed.) T F Sun. (Beijing: Pergamon Press) vol. 1

Ministry of Local Government, Housing and Construction 1980 Design of Buildings for High Winds, Colombo, Sri Lanka

Shanmugasundaram J and Arunachalam S 1990a Research Report, WEN-RR-90-4, SERC, Madras

Shanmugasundaram J, Arunachalam S and Arumugam M 1990b Research Report, WEN-RR-90-1, SERC, Madras

Shanmugasundaram J, Arunachalam S, Annamalai G and Arumugam M 1989 Proc. Natl. Symp. on preparedness, mitigation, management of natural disasters, New Delhi Vol. 1, New Delhi

Sparks P R, Baker J, Belville J and Perry D C 1985 Hurricane Elena Gulf Coast

Venkateswarlu B, Arumugam M and Arunachalam S 1985 Proc. Natl. Seminar on tall reinforced concrete chimneys, New Delhi

Venkateswarlu B and Muralidharan K 1978 Research Report, SERC, Madras

Wittenoom R A 1975 Proc. Annual Engineering Conference, The Institution of Engineers, Australia

Zornig H F and Sherwood G E 1969 Wood structures survive hurricane Camille's winds, USDA for Serv. Res. Paper. FPL. 123 